\title{
Understanding a digital movement of opinion: The case of \#RefugeesWelcome
}

\author{
Massimo Airoldi
}

Lifestyle Research Center, Emlyon Business School, France.

Email: $\underline{\text { massimo.airoldi@unimi.it }}$

Twitter: @massimoairoldi

Mauro Barisione (Corresponding Author)

Department of Social and Political sciences, University of Milan, Italy

Postal address: Via Conservatorio 7, 20122 Milano, Italy.

Email: mauro.barisione@ unimi.it

Twitter: @m_barisione

Asimina Michailidou

ARENA Centre for European Studies, University of Oslo, Norway

Email: asimina.michailidou@ arena.uio.no

Twitter: @AsiminaMi 


\section{Understanding a digital movement of opinion: The case of \#RefugeesWelcome}

Recent work on digital political engagement has extensively shown that social media platforms enhance political participation and collective action. However, the idea that citizen voice through social media can give rise, under given conditions, to a specific digital force combining properties of social movements and public opinion has received less attention. We fill this gap by analysing the digital discussion around the Twitter hashtag \#RefugeesWelcome as a case of 'digital movement of opinion' (DMO). When the refugee crisis erupted in 2015, an extraordinary wave of empathy characterized the publics' reactions in key European hosting countries, especially as a result of viral images portraying refugee children as the main victims. Using a triangulation of network, content and metadata analysis, we find that this DMO was driven primarily by social media elites whose tweets were then echoed by masses of isolated users. We then test the post-DMO status of the hashtag-sphere after a potentially antithetical shock such as the November 2015 Paris terrorist attacks, which polarized the network public. Overall, we argue that the concept of digital movement of opinion provides a heuristically useful tool for future research on new forms of digital citizen participation.

Keywords: social media; Twitter hashtags; refugees; public opinion, digital engagement; mixed methods 


\section{Introduction}

Over the last decade, citizen engagement through social media has been challenging established paradigms both of collective action and public opinion, whereby the first traditionally constituted a tangible, the latter a latent form of political participation. As the debate on new forms of political participation offered by new digital technologies is thriving (Koc-Michalska et al., 2016), most contributions tend to address social media as organizing agents and amplifying vehicles of collective action whose political force unfolds essentially on the streets, such as in the classical examples of the Arab springs, the Indignados, and the Occupy Wall Street movement (Bennett \& Segerberg, 2012; Castells, 2012; Gerbaudo, 2012; Anduiza et al., 2013). Even when authors focus specifically on the digital dimension of citizen engagement via social media (e.g. Papacharissi, 2015), they stop short of conceptualizing and capturing those particular cases whereby citizen voice arising from social media comes to combine traditional notions of public opinion and social movement into a new digitally based type of political force.

This article aims to fill a conceptual void by outlining the idea of 'digital movement of opinion' (DMO). This term, which we develop further in the following sections, refers to cases in which the general public actively uses social media platforms to react to a highly mediatized and emotionally charged event in a manner that creates the impression of a 
monolithic voice arising from social media. Hence, the concept of a digital movement of opinion overcomes both the survey-based notion of public opinion expressing the attitudes of a silent majority (Perrin \& McFarland, 2011) and the idea implicit in the social movement field whereby collective action entails non-digital (i.e. offline) mobilization by an active minority. Indeed, a DMO is a form of expression of public opinion - its constituent units are digital opinion statements - which, at the same time, shares with social movements the principle of one-sidedness, as well as being the property of a more active citizenry. While the latter is not representative of the general public, when it acts as a DMO it may come to embody a legitimate force in terms of public political discourse, and one influential on policy making.

Using a triangulation of unsupervised quantitative methods (Twitter network and metadata analyses) and more qualitative text-based validations, we show that the RefugeesWelcome hashtag, propagated primarily via Twitter at the beginning of the refugee crisis in September 2015, tends to adhere to the ideal-type of a DMO, with minor deviations from our conceptualization. Moreover, we test a set of hypotheses regarding the structure of the discussion network, the network users' mode of engagement, the degree of their interconnectedness, and the profile of the network's main influencers. For each element, we compare the hashtag-sphere at the peak phase of the DMO and two months 
later, in the aftermath of the - potentially antithetic - emotional shock represented by the Paris terrorist attacks in November 2015, insofar as it was the target of an anti-refugee political framing.

Overall, we argue that the DMO concept is heuristically useful for research on new forms of digital citizen participation, because it (1) provides an ideal-type allowing to study empirical cases by observing their adherence and deviations from the theoretical construct; (2) isolates the digital dimension of citizen participation, both as a methodological strategy and an epistemological posture; (3) bridges public opinion and social movement theories and thereby helps apprehend new/future forms - arguably more networked but also more individualized - of collective action.

The article is organized as follows: First, we briefly reconstruct the context of the 2015 refugee crisis in Europe. Second, we outline the notion of digital movement of opinion and illustrate the role of Twitter hashtags as facilitators/catalysts of DMOs. Subsequently, after presenting our theoretical expectations in regard to the features of the \#RefugeesWelcome DMO, we illustrate our research methodology and data. We finally present and discuss our findings, also in the light of future research on citizen digital engagement. 


\section{The context of \#RefugeesWelcome}

The refugee crisis has become a major issue for media scrutiny, public debate, citizen mobilization, and political decision-making in Europe since the summer 2015. The unprecedented influx of Syrian refugees fleeing the war and seeking to reach Western and Northern Europe via Greek islands and Balkan countries featured prominently in the news media agenda, with extensive coverage of the dramatic conditions and tragic events associated with the fleeing populations' journey to the EU.

Early news media coverage - between the end of August and the beginning of September 2015 - and social media feedback especially hinged on a number of symbolic images and defining moments which shaped the refugee crisis discourse in its genesis, such as the globally viral photos of 3-year-old Alan Kurdî's lifeless body on a Turkish beach and of the Syrian girl offering her biscuit to a Hungarian policeman while her compatriots were being forcefully repelled by border police. The powerful media imagery through which the refugee crisis was framed in this specific phase produced an extraordinary wave of empathy towards refugees within a relatively short time period. The established cleavage between the pro- and anti-immigration camps within and across EU countries seemed temporarily subverted as the national publics appeared to largely come together in support of the refugees' cause. ${ }^{1}$ 
This emotional wave of support impacted, in turn, on national and EU political leaders' discourse and policy (Holmes \& Castañeda, 2016), as famously exemplified by Angela Merkel ("Wir schaffen das", i.e. "We can do it") and David Cameron's claims about Germany and Britain's willingness respectively to accept and resettle a significantly high number of mainly Syrian refugees. A powerful manifestation of this relatively sudden wave of public empathy toward refugees was the Twitter hashtag \#RefugeesWelcome. Spreading through other social media platforms (Facebook, YouTube, Instagram, etc.), the hashtag quickly gained 'trending' status and filtered through in the offline public sphere where it became a politically relevant slogan (Refugees Welcome) in mainstream news media and in every-day, real-life public actions/protests. ${ }^{2}$

\section{Theoretical framework: Digital movement of opinion and Twitter hashtags}

While the idea that it is possible to detect unique aspects to digital activism is not new

(Bennett, 2003; Loader et al., 2013), research in this field has predominantly focused on the relationships between online and offline forms of citizen engagement (for meta-analytic reviews of the impact of social media use on citizen participation, see Boulianne, 2015; Skoric et al., 2016). In this view, social media have fundamentally expanded and complemented the social movement repertoire of collective action (Van Laer \& Van Aelst, 2010). 
In their influential contribution, Bennett and Segerberg (2012) have argued that the digital media, by ensuring the lowering of transaction costs for collective action, have favoured the emergence of a 'digitally networked action' (Bennett and Segerberg, 2012, p. 743) - or 'connective action' - bypassing Olson's (1965) classical problem of free riding. Participation in protest actions becomes easier, less costly, more flexible, and more personalized when it transcends conventional organizations based upon collective identities. If 'sharing' a post is the linchpin of connective action, however, the authors maintain that this kind of action, in order to be politically effective (Morozov, 2011) and sustained (Tilly, 2004), should be complemented by more conventional protest action on the streets. In other words, they see digital media functioning more as organizing agents than channels of expression for citizen protests.

The horizontal and participatory logic of social networking and microblogging platforms has given rise to what Castells (2009) named 'mass self-communication', that is a new form of communication adding to the well-established forms of mass and interpersonal communication. Even with all deficiencies and vulnerabilities of the digital dimension, web-based communication 'marks a new historical phase in the history of democracy' by enabling specifically new forms of participation (Dahlgren, 2013, p. 18). An emerging actor is what Papacharissi (2015) defines as 'affective networked publics', those transient publics 
that 'drive daily trending topics of conversation on Twitter' and are characterized by modalities of engagement that are 'sentiment driven and that form around structures of feeling'. However, these affective publics are seen as being a generalized expression of 'indignation, discontent, or disagreement' and are thereby confined to negative and hyperephemeral digital waves of emotions.

Our theoretical proposal aims to capture and emphasize the increasing and relatively autonomous importance of the online dimension of political participation by conceptualizing digital movements of opinion as a specific manifestation both of digital activism and social networking site (SNS)-mediated public opinion. In our formulation, which elaborates on Barisione and Ceron (2017), a digital movement of opinion (DMO) consists of spontaneous online mobilizations of the mass publics, which temporarily turn into an active public, usually as a reaction to a contingent, emotionally laden societal issue or policy measure. As such, DMOs are characterized by the presence of comments that are virtually one-sided (e.g. almost all negative toward a government decision, or positive toward 'refugees') and which usually express support of or protest against a policy associated with that issue. A DMO could be imagined as a social movement taking place online. $^{3}$ 
However, a number of qualifications differentiate a DMO from the classical notion of social movement, as per the latter's definitions by, for instance, Tarrow (1994) and Tilly and Wood (1995). In addition to being 'politically un-divided', the ideal-type of a DMO also presents the following features: it is 'socially un-categorized' or cross-cutting, since it involves members from the general public; 'formally un-organized' or ad hoc organizing, with no pre-established leadership or organizing network; and 'temporally un-sustained', meaning that it is relatively short-lived. As such, a DMO is best represented by an emotional wave of support or opposition that emerges from social media as a quasi-instant reaction to an event with a very high salience in the global media environment.

A DMO is typically driven by such emotions as compassion and empathy (for movements of support) or anger and indignation (for protest and opposition movements). Its emotional nature constitutes at the same time its force and its weakness. On the one hand, the activating emotion functions as a self-legitimizing principle for the DMO and enables it to reach peaks of intensity that virtually prevent dissenting voices from appearing in the digital public space, unless at the cost of being verbally violently stigmatized. On the other, this emotional basis condemns the DMO to a relatively short life-span (i.e. in the order of days or weeks), unless it comes to structure itself as a social movement, thereby losing its DMO status. Finally, the presence of non-digital action, such as marches, 
demonstrations or flash-mobs, can be a tangible extension of a DMO, albeit not a constitutive prerequisite for it. $^{4}$

Twitter hashtags - the key words adopted by users as tags to identify a topic for discussion - provide research on DMO with a powerful tool for analysis. Using a hashtag can be seen as 'an explicit attempt to address an imagined community of users' (Bruns \& Burgess, 2012, p. 3). This discursive public, which often arises around breaking news, is characterized by strong flexibility (Baym \& boyd, 2012). Indeed, users can communicate around the hashtag topic without having to establish follower/followee relationship with other participants. Therefore, hashtag-based networks structured around simple retweet, reply or mention relations are particularly suitable for the type of longitudinal analyses tracking network variations over time, which are required for locating and profiling a DMO. These communicative networks allow us to track topics that do not reflect only a single, isolated piece of breaking news, but a wider process or a more complex chain of events, such as protests against \#Austerity policies in Europe (Barisione \& Ceron, 2017) or mobilizations against \#DilmaRoussef in Brasil (Calvo et al., 2016). Moreover, if the general topic is addressed by main hashtag \#X, other hashtags linking to it may offer more nuanced frames for the same topic and can therefore denote an interpretation, a judgment or a possible remedy for the issue on hand. 
As discussed in the introduction of our article, the hashtag \#RefugeesWelcome is a specification of the more general topic of the ongoing refugee crisis in Europe. Assertive hashtags such as \#RefugeesWelcome thus function as frames, in that they 'promote a particular problem definition, causal interpretation, moral evaluation, and/or treatment recommendation for the item described' (Entman, 1993, p. 52). Indeed, this hashtag clearly asserted a moral orientation in its initial stage (i.e. before it was re-appropriated, as frequently happens with hashtags generally (Jackson \& Welles, 2015), in this case by antirefugee networks) with direct political and policy instructions in favour of receiving and helping refugees who were at the time seeking to reach the more affluent European countries. In other words, there was much more to \#RefugeesWelcome than a theme - there was a 'fusion of theme and opinion' (Luhmann, 1971), or 'collections of opinions, facts, and emotion' (Papacharissi, 2015, p. 129).

To be sure, the presence of a hashtag with an explicit frame in the Twittersphere is not sufficient to detect a digital movement of opinion. We recall that the preconditions for the existence of a DMO are (a) an emotion-laden event or issue (b) of public interest and with political relevance (c) which is largely covered in the news media. Thus, the emergence of a DMO encapsulated by a hashtag requires three defining conditions to be 
fulfilled, the first of which is quantitative, another is qualitative, and the last one is temporal.

(1) For the quantitative dimension, rather than indicating a fixed threshold we simply suggest that a message should be circulated and shared broadly throughout social media platforms, as to reach a mass audience. In this case, the 'mass self-communication' (Castells, 2009) nature of \#RefugeesWelcome is already suggested by its wide transnational reach. $^{5}$

(2) The qualitative indicator regards the direction (pro or against) of the opinions expressed by those participating, which should be unilateral (or quasi-unilateral) during the peak phase of the DMO. Even though this element seems to be implicit in \#RefugeesWelcome, homogeneity of the network structure needs to be further corroborated by mixed-method analysis.

(3) Thirdly, a DMO implies a life cycle that cannot be achieved within a few hours or one day, even though its online social networked nature renders it unlikely, as stated above, to be sustained over a long time period. In order to identify the final stage of a hashtag's life cycle - i.e. when a DMO dies out - analysis of the quantitative and qualitative 
conditions should be combined by looking not only at the relative decline in occurrences over time, but also at possible erosion in the one-sidedness of the hashtag's use.

Having already described the historical juncture and the symbolic elements which make the contextual pre-conditions satisfied in the case of \#RefugeesWelcome, we provide more fine-grained evidence of the temporal condition in the 'Data and measures' section.

Our fundamental expectations related to the DMO nature of \#RefugeesWelcome concern primarily the structure of the discussion network and subsequently the network users' mode of engagement, the degree of their interconnectedness and the profile of the network's main hubs. First and foremost, we expect to find evidence of strong network homogeneity in terms of pro-refugee attitudes, at least at the apogee of the hashtag's life cycle. Since the first feature of a digital movement of opinion is having a unidirectional stance, all the main network hubs - those which are most often duplicated by users - should express a genuine pro-refugee message. Conversely, given that a new peak is detectable in the hashtag's occurrences after the terrorist attacks in Paris, we anticipate that network homogeneity should vanish among \#RefugeesWelcome users as a consequence of this emotional - potentially antithetic - shock breaking into the public agenda, and that attitude polarization may possibly come to characterize the discussion about refugees and related policies. ${ }^{6}$ 
As for the subsequent elements (the network users' mode of engagement, the degree of their interconnectedness and the profile of the network's main influencers), our further hypotheses point to the reactive, mass-based and hierarchical (i.e. dependent on social media elites) nature of a digital movement of opinion. We spell out these expectations in the next section, in conjunction with the presentation of our research methodology.

\section{Triangulating Twitter network, metadata and content analysis}

Our approach has three methods at its core - namely, users' metadata analyses, network mapping, and qualitative content analysis. We opted for a multi-method approach of analysis, which allowed us not only to quantitatively measure different components but also to triangulate our findings and thus increase the reliability of our results (Erzberger \& Kelle, 2003).

Network analysis is now a widely popular approach in the field of online research, in particular in the study of Twitter (Bruns \& Burgess, 2012; Calvo et al., 2016). The 'natively' networked character of social network sites like Twitter makes network analysis a particularly suitable tool to track and map the patterns of social interaction underlying a discursive field such as \#RefugeesWelcome (Rogers, 2013). Mapping Twitter conversation 
networks can provide important insights into a discursive field or a public discussion over a societal or political issue, without or before engaging in any kind of text analysis.

Firstly, metadata drawn from social media networks reveal information about individual participants and their connections with other individuals. The role of single participants can be assessed based on the number and nature of their connections, which can make them act as 'hubs', 'bridges' or 'isolates' within each network (Smith et al., 2014). In the language of social network analysis, 'edges' may be given, in turn, by relationships between participants in terms of following, mentioning, replying or retweeting. These micro-level data are useful to discover the kinds of interactions that take place in different public conversations on Twitter or any other social media. In order to capture the nature of a DMO such as \#RefugeesWelcome, a crucial, first step is to identify the main hubs (i.e. those Twitter accounts whose tweets reporting the hashtag were retweeted most often) and to assess the weight of isolates (i.e. those who posted a tweet or retweeted someone else's tweet without being connected to any other participant within the network).

We then combine these results with quantitative and qualitative analysis of users' metadata (number of followers, location, public profile description, number of retweets for specific message, language) and of message contents. We do this in order to shed light a) 
on the elite- vs. citizen-driven nature of the DMO, by determining who the top influencers are, and b) on the type of participation fostered by the particular hashtag network, by identifying whether \#RefugeesWelcome brings together interconnected followers (networked participation) or isolated users (a mass-audiences type of participation). Our expectations in this regard point to the essentially elite-driven nature of the DMO. By social media elites we mean Twitter accounts belonging to institutions, NGOs, news media, celebrities, and Twitterpreneurs. ${ }^{7}$ This expectation is consistent with previous studies detecting news media sources and highly active users/political activists as the typical initiators and leaders of movement and discussion networks (Segesten \& Bossetta, 2016; Bailo \& Vromen, 2016; Papacharissi, 2015). For the same reason, we expect participants to duplicate the social media elites' tweets rather than to retweet each other and the resulting network to be highly hierarchical. This should also reflect the prevalently mass-based nature of a DMO, whose participants - different to the offline-bundled outcome of digitally networked action (Bennett \& Segerberg, 2012; Maireder \& Shwarzenegger, 2012) - tend to be isolated (i.e. non-interconnected) users, also due to the large-scale and transnational nature of the issue under discussion.

Secondly, network analysis provides group-level information that is typically visualized as network maps. Social media network maps are like 'aerial crowd 
photographs' in a public square and can thus provide useful information about the rough size and structure, for instance, of a Twitter community formed around a given topic or hashtag (Smith et al., 2014). Patterns of opinion homogeneity versus polarization may emerge through an aerial view of the networked structure of a digital conversation. A polarized-crowd structure is a typical indicator of 'ideological sorting' in online communication (Barberá et al., 2015; Colleoni et al., 2014), with discussion networks split in two groups (or echo-chambers) of politically like-minded individuals driven by mechanisms of attitude homophily and/or selective exposure to consonant sources of information. Mapping the relationships among those who tweet about a certain issue allows the identification of users who are part of highly connected subnetworks or clusters (Himelboim et al., 2013). Even though social media may increase the size and diversity of individuals' personal communication networks (Barberá, 2014), certain topics seem to favour the formation of relatively disconnected conversational communities, where patterns of attitude reinforcement and polarization prevail over chances of attitude change. By adding content analysis to network analysis (Ogan \& Varol, 2016), we expect to find evidence - as illustrated in the previous section - of network homogeneity at the apogee of what we hypothesize to be a pro-refugee $\mathrm{DMO}$, and network polarization as a consequence of the terrorist attacks. 
A final point concerns the issue of whether the \#RefugeesWelcome DMO functioned as an echo or 'refraction' chamber. Rieder (2012) captures the potential diversity of the online public sphere with the term 'refraction chamber': even when tweets concerning an event are repeated (retweeted) thousands of times, they might not always be exactly the same. Echo and refraction serve as definers of the type of user engagement: in the first case, a message is reproduced as a result of unquestioned dominant influencers; in the latter, as a result of the Twitter user's proactive decision to adopt and adapt the message. This may also indicate different degrees of voice inclusiveness (space allowed for multiple opinions and voices), which is by definition minimal in an echo chamber-like communication environment (Michailidou, 2017). Given our expectations about the network's homogeneous, hierarchical and elite-driven structure and dynamics, we also expect the \#RefugeesWelcome DMO to be largely characterized by message duplication and thus function as an echo (reactive) rather than as a refraction (proactive) chamber. However, we hypothesize that the degree of message refraction may increase in conjunction with network polarization after the Paris attacks. In the following section we present in more detail the measures and data we have used to investigate our DMO concept in relation to the \#RefugeesWelcome case.

\section{Data and measures}


Although hashtag use is now well entrenched across all social media and microblogging sites to classify user content, it was on Twitter in particular that hashtags first appeared as an 'organic' way for Twitter users to make sense of the otherwise asynchronous communication environment of that particular social media platform (Scott, 2015). It is for this reason, as well as due to Twitter's consistent position as one of the most influential social media platforms worldwide, that we focused on the use of \#RefugeesWelcome specifically on Twitter. We have used a social media analytics tool designed for tracking Twitter content (hashtagify.me by Cybranding Ltd, 2016) to monitor and collect a large amount of tweets featuring the hashtag \#RefugeesWelcome. Our resulting dataset comprises more than 1 million tweets containing \#RefugeesWelcome $(1,206,277)$, ranging from September 2015 to April 2016. ${ }^{8}$ It includes the text of each tweet, together with several metadata such as the tweet's date and language, as well as the author's nickname, bio, location, number of followers, mentions of other Twitter users and number of retweets.

The distribution of tweets over time (Figure 1) shows a general decrease in the use of \#RefugeesWelcome after the first weeks of September 2015. While a new peak can be observed by the mid of November 2015, the hasthtag's decline in visibility is evident over the following months. Only very minor increases are detectable in January, after the media reported on the New Year's Eve mass sexual assaults in Cologne by groups of male 
migrants, and in March 2016, after the terrorist attacks in Brussels. Overall, evidence suggests that the hashtag's salience came to an end by early December 2015, even though it did not completely disappear from the Twittersphere after that point in time.

[Figure 1 here]

Initial analysis of hashtag co-occurence for \#Refugees Welcome, i.e. other hashtags simultaneously used with this particular hashtag, shows that \#RefugeesWelcome was the leading hashtag, used essentially to frame more neutral or more general hashtags such as \#refugees (which co-occurs with \#refugeeswelcome on $7,23 \%$ of cases in the overall dataset), \#refugeecrisis (3,80\%), \#syrianrefugees (2,31\%), and \#refugeescrisis (1,54\%). The hashtag network for \#RefugeesWelcome also reflects the change in use of the particular hashtag, whereby as the popularity of the particular hashtag begun to decline, it was used also in a negative context, such as the Paris terror attacks.

Subsequently, using an ad hoc Python script, we obtained and imported a list of edges in the network analysis and visualization software Gephi (2016), so as to map out and analyse the networked structure of the digital debate. On Twitter, we can distinguish between two overlapping and interdependent networks - one based on the relatively stable follower-followee relationship, another based on the short-term and emergent 
communicative interactions surrounding topics and hashtags (Bruns \& Burgess, 2012, p. 2). We focused on this second, more transient type of Twitter network.Further to describing the overall \#RefugeesWelcome network, we identified core indicators to address our DMOrelated hypotheses, and we combined our three different techniques (metadata, network, and qualitative content analyses) to process the data and triangulate our findings.

We focused our analyses on two subsets of tweets: those from one peak and one off/peak date within this period: 12 September 2015 (74,807 tweets collected) and 14 November 2015 (12,740 tweets). While in the peak of September 12 we expected to capture the apogee of a pro-refugee DMO, by selecting November 14 (the immediate aftermath of the terrorist attacks in Paris) as our second date, we aimed to test the hypothesis that this event, if framed in anti-refugee terms by social media actors, would produce a polarized hashtag-based network as a consequence of the countervailing emotional context newly generated.

In our network analysis, Twitter users represent the nodes (or vertices). An edge is established when, for instance, node A retweets node B. The number of interactions between the two determines the weight of the edge. As a measure of users' influence in the debate, we employed the nodes' in-degree, that is, the number of RTs they received. While Twitter mentions can be critical or explicitly negative, retweets are much more consistent 
indicators of support for a Tweet's account and content, at least in the political sphere (for example, Makazhanov et al., 2014). Isolated users are those having a 0 in-degree, while influencers - namely, those largely retweeted - are central hubs in the network (Smith et al., 2014). The rate of isolates over the total amount of nodes in the network allows us to determine if and when the \#RefugeesWelcome public functioned as an interconnected or a mass-public network.

In a second step, we used DiscoverText (Texifter, 2016) in order to calculate the extent of message duplication, by retrieving for each tweet its status of seed, duplicate, or near-duplicate within the \#RefugeesWelcome network on the selected dates of 12 September and 14 November 2015. Specifically, seed messages are original tweets created by unique users, while items are considered to be duplicates if they replicate verbatim a seed tweet as a retweet. Near-duplicates are retweets of the same content but with smaller or more extensive changes to the content, such the addition of a mention other than the original source of the retweeted message, or the addition/removal of certain words from the original tweet, but which do not substantially alter the original tweet's content or meaning. Our core assumption in this regard is that the higher the share of duplicates, the more reactive (rather than proactive) a hashtag-sphere is. 
We then created visual maps of the results using Gephi (2016), which depict the network's homogeneous versus polarized structure. Pro/against refugee clusters in the networks were detected on the basis of the manual analysis of the tweets authored by the main hubs ${ }^{9}$, and then visually indicated by distinct colours. Finally, we profiled the creators of the seed tweets according to 11 broad categories of actors (citizens, ${ }^{10}$ social media entrepreneurs, ${ }^{11}$ news sources,${ }^{12}$ experts,${ }^{13}$ national politicians, national political institutions, EU politicians, EU political institutions, NGO activists/representatives, actors/singers/celebrities and spiritual leaders ${ }^{14}$ ). In the next section we report the main findings of our study.

\section{Results}

The overall profile of the network of Twitter users using \#RefugeesWelcome between September 2015 and April 2016 is visually illustrated in Figure 2. Labels highlight the main hubs - that is, the authors of tweets that have been retweeted or mentioned at least 500 times. These are mainly NGOs (e.g. @amnesty, @oxfam), political institutions (e.g. @whitehouse), celebrities (e.g. @harry_styles, member of the band One Direction), politicians and news media. The different colours in the visualisation correspond to different clusters in the network, that is, tight groups of users having frequently interacted together, identified through Gephi's community detection algorithm ${ }^{15}$. Most of the clusters 
are country-based, such as the green British one (featuring e.g. @savechildrenuk, @david_cameron), the Spanish one (in purple, e.g. @amnistiaespana,@madrid), and the German one (in orange, e.g. @bild, @fcstpauli). Another distinct cluster, depicted in blue colour, is the one comprising extreme right-wing activists ${ }^{16}-$ e.g. Tommy Robinson (@trobinsonnewera), ex leader of the British anti-Islamist movement 'English Defense League').

[Figure 2 here]

\section{\#RefugeesWelcome DMO peak: 12 September 2015}

Figure 3 illustrates the \#RefugeesWelcome RT network as it looked on the $12^{\text {th }}$ of September 2015. On this peak date we collected 74,807 tweets. Every time a user retweeted another one in this time span, we established a directed edge between the two, whose 'weight' depended on the number of interactions - meaning, for instance, weight 1 in the case of one RT, weight 2 in the case of two RTs, and so on. Thereby, we derived a network made of 39,463 nodes (the users), linked by 53,570 edges. By manually coding the pro/anti-refugees character of the main hubs (Figure 3), we were able to map out the ideological homogeneity of September 12 \#RefugeesWelcome's Twitter public. As the homogeneous blue shade in Figure 3 shows, all of the twenty main hubs were pro-refugees. 
Their opinion was mirrored by a large portion of the \#RefugeesWelcome public, each of them being retweeted by an average of 694 users. This clearly corroborates our expectation about a homogeneous hashtag-sphere reflecting a DMO.

Further analysis of the content and metadata of the tweets produced on 12 September 2015 shows that of the 74,807 items found in the original archive for that date, less than a third (27.4\%) were single items (without duplicates). This predominance of duplication indicates a relatively high degree of echo and demonstrates that users, albeit acting as diffusers of the moral stance encapsulated in the seed tweets' hashtag, are not proactive in refracting the message and the pool of original statements or views remains very limited.

Twitter users deployed the hashtag \#RefugeesWelcome to call their followers to solidarity, such as the top seed message 'Take a stand with us \& @savechildrenuk: help make \#RefugeesWelcome' which was twitted by British singer-songwriter and member of music band One Direction, Harry Styles on 5 September 2015. Harry Styles's tweet had 2,835 verbatim duplicates in our 12 September 2015 dataset and was directly retweeted over 122,585 times from his Twitter account, making it also the most visible \#RefugeesWelcome tweet throughout the entire monitoring period. The tweet included a link to the homepage of Save the Children UK containing a strong plea for aid to child 
refugees, thus contributing to framing the \#RefugeesWelcome message in terms of a 'children as victims' frame, which we find often among the most-duplicated tweets in combination with video or photographic material, such as the following: 'Heartbreaking: a Syrian child offers cookies to policemen who are blocking his way to safety \#refugeeswelcome' (author: twitterpreneur @ ProteinShaykh).

Another common frame is that of 'active support', whereby the \#RefugeesWelcome hashtag is used to highlight a positive action/mobilization in support of the refugees trying to make their way to Europe, again often accompanied by photographic or video material, such as the following: ‘Arsenal fans. \#RefugeesWelcome', tweeted by @TSBible, the official Twitter profile of a UK-based sports platform with global reach (750 duplicate units in our 12 September dataset, 915 direct retweets from profile).

As the prevalence of a reactive mode of engagement indicates, the 12 September 2015 online discussion around \#RefugeesWelcome is dominated by a small number of hubs frequently retweeted by a large number of non-influential users. This interpretation is also confirmed by the high rate (about $80 \%$ ) of isolates - users having in-degree equal to 0 since they have not been retweeted by anyone. Of the 53,570 interactions constituting our RTnetwork, $26 \%$ involve the twenty top hubs, which means that non-influential users instead of retweeting each other only tend to retweet the main hubs. 
[Figure 3 here]

Nearly half of the 20 top hubs in our \#RefugeesWelcome dataset for September 12 were by influential social media entrepreneurs (3) and celebrities (actors, authors and singers; 6), with the Pope (2), citizens (3), a UK politician (1), experts/professionals (2) and a Danish photoreporter (2) completing the list. Non-governmental organizations with international influence and with or without expertise on the issue of refugees, such as Amnesty International, Save the Children, and the Human Rights Watch weighed in the \#RefugeesWelcome Twitter debate, endorsing the positive message of the hashtag in this initial phase, although only one NGO (Save the Children) made it to the Top 20 hubs. Our overall conclusion in this respect is that the September peak in the hasthag's use represents a fairly homogeneous network that was strongly driven by what we have defined as 'social media elites', followed and echoed by large numbers of isolated individual users.

\section{\#RefugeesWelcome on 14 November 2015}

Just after the Paris' terrorist attacks on the 13th November 2015, the \#RefugeesWelcome digital debate is notably different, as a comparison between Figure 3 and Figure 4 (below) illustrates. ${ }^{17}$ The 14 November \#RefugeesWelcome RT network is much smaller, containing 12,146 nodes and 12,454 edges. The assessment of the pro- or 
anti-refugee character of the top twenty hubs on that date shows that, contrary to the situation on the peak DMO date of 12 September, 13 out of 20 hubs are anti-refugee (in red; Figure 4 below). On November 14, 2015, \#RefugeesWelcome became a discursive field where xenophobe, anti-Islamic users gained salience and visibility, thus partly claiming control of a hashtag created for the opposite reason.

[Figure 4 here]

The following RT is an example of this symbolic appropriation: 'We tried to warn you. \#refugeeswelcome blood is on your hands', tweeted by @TRobinsonNewEra, a Twitterpreneur and xenophobic political activist (141,000 followers, 334 duplicates in dataset and 370 retweets from profile). Another example is the French-language tweet 'C'est donc pour ça que l'on quitte son pays... \#refugeeswelcome \#portesouvertes' ('So this is why they leave their country... \#refugeeswelcome \#opendoors'; author: the pro-French National Front account @HumourDeDroite [Right-wing humour], 285,000 followers, 285 duplicates).

Nevertheless, the single most duplicated item on November 14 was clearly prorefugee: @Chikosdelmaiz, a Basque left-wing music band (98,100 followers, 2,482 duplicates) invited readers to imagine how life must be for people fleeing from Syria, 
where tragedies like those in Paris happen every day ('Imagina lo de Paris en tu barrio. A diario. Durante años. Entonces huyes de la barbarie y te reciben como si fueras gana?'). Overall, therefore, the discussion network now appears to be strongly polarized between pro- and anti-refugees.

Further analysis of the content and metadata of the tweets produced on 14 November 2015 shows that of the 12,740 items in our dataset, a mere 4 per cent (613) were single items (without duplicates), while the rest (12,127 items) were classified in a total of 846 groups (the seed tweet plus all its exact duplicates). Contrary to our expectations, the degree of echo in the mode of users' engagement with the topic is even higher than during the DMO early stage of the hashtag: Echoing increases across two rival echo chambers, resulting in a lot of replication and minimal interaction or mentions of other Twitter users, besides those who we identify as main hubs. This is possibly due to the fact that this network is clearly smaller, both in terms of overall number of nodes $(12,146$ versus 39,463$)$ and diameter (6, as opposed to 21$)$.

Despite this substantial shift from pro-refugee DMO to highly polarized digital crowd, the public of \#RefugeesWelcome the day after Paris terrorist attacks is mainly composed, as in the case of 12 September 2015, of isolates with in-degree equal to 0 (about $90 \%$ of users). Besides, the twenty top hubs are, in this case, involved in the majority of 
total interactions $(52 \%)$. As a result, the 14 November network is a particularly hierarchical one.

Finally, a variety of multilingual social media entrepreneurs (mainly left- or rightwing political activists; seven in total, three of anti-refugee sentiment and four pro-refugee) dominate the \#RefugeesWelcome sphere on 14 November 2015, along with news media (2), NGOs or members of NGO/activist organisations (3), politicians (2), the Pope (2), celebrity actors and singers (2) and citizens (2). This is in contrast to the more homogeneous, and all-English, social media elites' mix of celebrities, Twitterpreneurs and news sources that we found on 12 September.

\section{Conclusion}

Overall, these results provide new insights into understanding the logics and dynamics of digital movements of opinion (DMO), an emerging political force arisen from social media platforms and combining properties of social movements and public opinion, and which more importantly - cannot be reduced to either one of these established forms of participation. 
Our study has shown that the hashtag \#RefugeesWelcome gained momentum and rose to DMO status in the early stages of its life cycle. The massive numbers of this elitedriven but homogeneously pro-refugee network, at least in the initial peak of September, created a powerful digital public voice which, in conjunction with its offline extensions, provided broad legitimacy to governments and NGOs carrying out their work with refugees. While the discussion was dominated by influential actors such as NGOs, news sources, social media entrepreneurs and above all celebrities from the entertainment industry (in line with Arvidsson et al., 2016 on the influence on Twittersphere of music celebrities in particular), the presence of a large periphery of 'isolates' endorsing and diffusing the pro-refugee message of \#RefugeesWelcome without being connected to any other participant suggests an important mechanism of a DMO: masses of isolated digital citizens are mobilized by a common emotional reaction over a large-scale issue (whereas more local tags may display denser connectivity between posting users: Yardi \& boyd, 2010).

However, two defining features of a DMO - having massive numbers and homogenous orientations (i.e. with almost all reactions being pro-refugee) - were already challenged in the following weeks, when it became clear that the refugee crisis would be a permanent issue on the public agenda for the foreseeable future. After its statu nascendi 
phase, the refugee crisis was to regain its status of a highly divisive issue (Holmes \& Castañeda, 2016). The hashtag's gradual decline after a few weeks thereby reflects the corresponding decay of this pro-refugee movement of opinion, all the more extraordinary that it came to virtually monopolize, albeit for a relatively short time, the citizens' voice on such a politically controversial issue. When the hashtag, after the Paris terrorist attacks, momentarily resurged from its stagnation, it no longer stood for a digital movement of opinion (which no longer existed as such), but was the object of a symbolic appropriation on the part of the anti-refugee camp portraying refugees as a 'Trojan horse' of ISIS terror in Europe. The discussion network now clearly displayed polarization rather than homogeneity, with a more intense struggle over the public representation of refugees (e.g. helpless children and deserving victims vs. overwhelming flood of potential terrorists) and a tougher 'war of position' over symbols and their meanings.

In addition to providing a sort of ideal-typic construction against which empirical cases of digital citizen participation can be compared and analyzed, the concept of DMO is heuristically useful because it captures a process of public opinion over salient issues which clearly deviates from normal patterns. When an issue - such as, for instance, the flow of refugees - is largely mediatized, that is, thematized and made salient through mainstream and digital media, it becomes customarily the object of opinion debate and/or conflict 
between political and social groups. Opinion diversity, or divisiveness, is thus the norm in the public sphere. But in some cases, especially as a consequence of highly emotional events largely covered by the media and becoming viral through social networks, only one manifestation of opinion tends to acquire public legitimacy. The property of opinion homogeneity (or virtual one-sidedness), at least in its legitimate public manifestations, thus defines the theoretical distinctiveness of a digital movement of opinion, which is a relatively new phenomenon associated with the mass-reactive nature of the social media environment. Our case study shows an example that approximates to the idea of a DMO, but also the subsequent resilience of a "normal" state of opinion division over the issue under consideration.

Of course, the usual caveats apply to this Twitter-based study, from controversial representativeness of Twitter's public API (Driscoll et al., 2014; Lewis et al., 2013) to potential distortions caused in public debates due to content contributed by bots (Bessi \& Ferrara, 2016; Cook et al., 2014; Murthy et al., 2016). However, these concerns are less compelling in our study, as our aim was not to estimate exact percentage distributions of pro- and anti-refugee attitudes, but to shed light on the structure and dynamics of what we consider as an increasingly important form of political engagement in the digital era. 
Admittedly, the explicit strategy of this study, which consists of isolating a single the most widely used and the most symbolic - hashtag, the one coming closer to satisfy the "mass audience" defining condition of a DMO, also presents some limitations. Ideally, a holistic study of the field of forces (positive and negative, digital and associational, etc.) in conflict around the issue would provide a more comprehensive picture. In addition to considering other social media platforms than Twitter, future studies on DMOs could move towards a more comprehensive research design by analysing more systematic patterns of interaction between a key DMO hashtag and other relevant hashtags, as well as developing a filtering system that would allow us to capture the extent to which fake or managed Twitter or other social media accounts affect the rise and fall of DMOs, and therefore impact on the democratic quality of the digital public sphere.

Acknowledgements

[Removed for review]

Funding

[Removed for review] 


\section{References}

Anduiza, E., Cristancho, C, \& Sabucedo, J. (2013). Mobilization Through Online Networks: The Political Protest of the Indignados in Spain. Information, Communication \& Society, 17(6), 750-764.

Arvidsson, A., Caliandro, A., Airoldi, A. \& Barina, S. (2016). Crowds and value. Italian Directioners on Twitter. Information, Communication \& Society, 19(7), 921-939.

Bailo, F., \& Vromen, A. (2016). Hybrid social and news media protest events: from\# MarchinMarch to\# BusttheBudget in Australia. Information, Communication \& Society, 1-20. http://dx.doi.org/10.1080/1369118X.2016.1252410

Barberá, P. (2014). How social media reduces mass political polarization. Evidence from Germany', Spain, and the US. Job Market Paper, New York University.

Barberá, P., Jost, JT, Nagler, J, Tucker, JA \& Bonneau, R. (2015). Tweeting From Left to Right: Is Online Political Communication More Than an Echo Chamber? Psychological Science, 26(10),1531-1542.

Barisione, M, \& Ceron, A. (2017) A digital movement of opinion? Contesting austerity through social media. In M. Barisione \& A. Michailidou (Eds), Social Media and European Politics: Rethinking Power and Legitimacy in the Digital Era (pp. 89118), Basingstoke and London: Palgrave Macmillan. 
Baym, N. \& boyd, d. (2012), Socially mediated publicness: an introduction. Journal of Broadcasting \& Electronic Media, 56(3), 320-329.

Bennett, L. W. (2003). Communication Global Activism: Strengths and Vulnerabilities of Networked Politics, Information, Communication \& Society 6:2, 143-168.

Bennett, W. L., \& Segerberg, A. (2012). The logic of connective action. Information, Communication \& Society, 15(5), 739-768. doi: 10.1080/1369118X.2012.670661

Blondel, VD., Guillaume, J., Lambiotte, R. \& Lefebvre, E. (2008). Fast unfolding of communities in large networks. Journal of Statistical Mechanics: Theory and Experiment, 8, 1-12.

Boulianne, S. (2015). Social media use and participation: a meta- analysis of current research. Information, Communication \& Society, 18:5, 524-538. doi: $10.1080 / 1369118 X .2015 .1008542$

Bruns, A. \& Burgess, J. (2012). Researching News Discussion on Twitter: New Methodologies. Journalism Studies, 13(5-6), 801-814.

Calvo, E., Dunford, E., \& Lund, N. (2016). Hashtags that Matter: Measuring the propagation of Tweets in the Dilma Crisis. Research note. Available at: https://www.researchgate.net/publication/306275910_Hashtags_that_Matter_Measur ing the propagation_of Tweets in the Dilma_Crisis (accessed 10 September 2016). 
Castells, M. (2009). Communication Power. Oxford, New York: Oxford University Press.

Castells, M. (2012). Networks of outrage and hope: Social movements in the Internet age. Cambridge: Polity Press.

Colleoni, E. Rozza, A. \& Arvidsson, A. (2014). Echo Chamber or Public Sphere? Predicting Political Orientation and Measuring Political Homophily in Twitter Using Big Data. Journal of Communication, 64(2), 317-332.

Cook, DM., Waugh, B, Abdipanah, M., \& Hashemi, O. (2014). Twitter Deception and Influence: Issues of Identity, Slacktivism, and Puppetry. Journal of Information Warfare, 13(1), 1-11.

Dahlgren, P. (2013). The political web: Media, participation and alternative democracy. London: Palgrave Macmillan.

Diani, M. (2000). Social movement networks virtual and real. Information, Communication \& Society, 3(3), 386-401.

Driscoll, K. \& Walker, S. (2014). Big Data, Big Questions| Working Within a Black Box: Transparency in the Collection and Production of Big Twitter Data. International Journal of Communication, 8, 1745-1764.

Entman, RM. (1993). Framing: Toward clarification of a fractured paradigm. Journal of Communication, 43(4), 51-58. 
Gephi.org (2016). Gephi: The open graph viz platform. Available at: https://gephi.org/ (last accessed: 10 November 2016).

Gerbaudo, P. (2012). Tweets and the streets: Social media and contemporary activism. London: Pluto Press.

Himelboim, I., McCreery, S. \& Smith, M. (2013). Birds of a feather tweet together: Integrating network and content analyses to examine cross-ideology exposure on Twitter. Journal of Computer-Mediated Communication, 18(2), 40-60.

Holmes, SM. \& Castañeda, H. (2016). Representing the "European refugee crisis" in Germany and beyond: Deservingness and difference, life and death. American Ethnologist, 43(1), 12-24.

Jackson, S. J. \& Foucault Welles, B. (2015). Hijacking \#myNYPD: Social Media Dissent and Networked Counterpublics. Journal of Communication, 65, 932-952. doi: $10.1111 /$ jcom. 12185

Koc-Michalska, K. Lilleker, D. \& Vedel, T. (2016). Civic political engagement and social change in the new digital age. New Media and Society, 18(9), 1807-1816.

Lewis, SC., Zamith, R. \& Hermida, A. (2013). Content Analysis in an Era of Big Data: A Hybrid Approach to Computational and Manual Methods. Journal of Broadcasting \& Electronic Media, 57(1), 34-52. 
Loader, B., Steel, H., \& Burgum, S. (2015). Introduction to Virtual Special Issue: Social Movement Protest and Organization. Information, Communication \& Society, http://explore.tandfonline.com/content/ah/ics-vsi/social-movement\#23092

Luhmann, N. (1971). Offentliche Meinung. In N. Luhmann (Ed.). Politische Planung, Opladen: Westdeutscher Verlag.

Maireder, A. \& C. Shwarzenegger (2012). A Movement of Connected Individuals: Social media in the Austrian student protest 2009. Information, Communication \& Society, 15(2), 171-195.

Makazhanov, A., Rafiei, D. \& Waqar, M. (2014). Predicting political preference of Twitter users. Social Network Analysis and Mining, 4(1), 1-15.

Michailidou, A. (2017). Twitter, public engagement and the Eurocrisis: More than an echo chamber? In M. Barisione \& A. Michailidou (Eds.) Social Media and European Politics: Rethinking Power and Legitimacy in the Digital Era (pp. 275-300). Basingstoke and London: Palgrave Macmillan.

Morozov, E. (2011). The Net Delusion: How Not to Liberate the World. London: Allen Lane.

Murthy, D., Powell, AB., Tinati, R., Anstead, N., Carr, L., Halford, SJ., \& Weal, M. (2016). Automation, Algorithms, and Politics| Bots and Political Influence: A Sociotechnical Investigation of Social Network Capital. International Journal of Communication, 10, 4952-4971. 
Ogan, C., \& Varol, O. (2016). What is gained and what is left to be done when content analysis is added to network analysis in the study of a social movement: Twitter use during Gezi Park. Information, Communication \& Society, 1-19.

http://dx.doi.org/10.1080/1369118X.2016.1229006

Olson, M. (1965). The Logic of Collective Action: Public Goods and the Theory of Groups. Cambridge, MA: Harvard University Press.

Papacharissi, Z. (2015). Affective publics: Sentiment, technology, and politics. New York: Oxford University Press.

Perrin, A. J. \& McFarland, K. (2011). Social theory and public opinion. Annual Review of Sociology, 37, 87-107.

Rieder, B. (2012). The refraction chamber: Twitter as sphere and network. First Monday 17(11),1-16. doi: http://dx.doi.org/10.5210/fm.v17i11.4199 .

Rogers, R. (2013). Digital Methods. Boston, MA: MIT Press.

Scott, K. (2015). The pragmatics of hashtags: Inference and conversational style on Twitter. Journal of Pragmatics, 81, 8-20. doi:10.1016/j.pragma.2015.03.015.

Segesten, A. D., \& Bossetta, M. (2016). A typology of political participation online: how citizens used Twitter to mobilize during the 2015 British general elections. Information, Communication \& Society, 1-19. 
Skoric, M. M., Zhu, Q., Goh, D., \& Pang, N. (2015). Social media and citizen engagement: A meta-analytic review. New Media \& Society, 18(9), 1817-1839. doi: https://doi.org/10.1177/1461444815616221.

Smith, M.A., Rainie, L., Shneiderman, B. \& Himelboim, I. (2014). Mapping Twitter topic networks: From polarized crowds to community clusters. Part 2:

Conversational Archetypes: Six conversation and group network structures in Twitter. Report, Pew Research Center. Available at:

http://www.pewinternet.org/2014/02/20/part-2-conversational-archetypes-sixconversation-and-group-network-structures-in-twitter/ (last accessed 10 September 2016).

Texifter (2016). DiscoverText text analytics: http://discovertext.com (last accessed 10 August 2016), Massachusetts: Texifter LCC.

Van Laer, J. \& Van Aelst, P. (2010). Internet and Social Movement Action Repertoires: Opportunities and limitations. Information, Communication \& Society, 13(8), 11461171.

Zaller, J. (1992). The Nature and Origins of Mass Opinion. Cambridge: Cambridge University Press.

\footnotetext{
${ }^{1}$ The percentage of positive comments posted by Twitter users about refugees increased, for instance, by 14 points in France and by almost 40 points in Britain in the first week of September 2016 (Voices from the Blogs 2015), Available at: http://sentimeter.corriere.it/2015/09/11/la-tragedia-di-aylan-scuote-le-coscienze-degliinglesi-piu-che-degli-italiani/?refresh ce-cp (last accessed: 27 October 2016)

${ }^{2}$ Given the inherent interdependence between mainstream and social media in the present "hybrid" media environment, we do not consider as a strategic issue here the causal
} 
primacy of news media vs. social media in attributing to a topic the salience that is always necessary for the rise of a DMO.

${ }^{3}$ Unlike social movements, moreover, a DMO could arise in a pre-election context in support of a political candidate, for example in a scenario where an outlier candidate is brought into the electoral scene thanks to momentum generated or facilitated by a DMO. But once this candidate is brought into the electoral race, his/her continuing support, now confronted with political oppositions, falls under the umbrella of institutionalized electoral competition and is no longer a DMO.

4 The patterns of interaction between a DMO and non-digital manifestations of the same movement of opinion are analyzed in Barisione and Ceron (2017).

${ }^{5}$ https://twitter.com/twitter/status/639500090529288192 .

${ }^{6}$ We do not assume the second emotional shock to have a polarizing effect in abstracto. In fact, following the public opinion literature, this type of event may be compared to those (such as, typically, wars or "attacks to the nation") that trigger a "rally around the flag" effect, that is one of homogeneization. But in this case the shock eliciting in-group solidarity follows a pre-existing pattern of solidarity toward out-groups. Therefore, a polarized pattern results from the clash between two conflicting messages (Zaller 1992) triggering opposite "homogenizing" emotional reactions, one positive toward refugees (early September images), and the other potentially negative. Of course, imputation of responsibility to refugees for the Paris attack requires a specific work in terms of framing on the part of the messenger (Tweet producer). This is what we seek to analyze in the second part of the analysis.

${ }^{7}$ We define a Twitterpreneur as a Twitter user with over 1,000 followers, whose Twitter profile highlights their expertise in social media communications. They may also have a blog, website, Facebook page and/or Instagram profile. A Twitterpreneur need not be a professional expert in a field. Their main qualification is their large number of followers due to them being recognized as influential actors within the Twittersphere.

${ }^{8}$ Hashtagify.me accesses Twitter's REST API, with the parameter to download "all" tweets relevant to a hashtag and not only the most popular ones (in order to avoid a bias in the data towards big influencers). Hashtagify.me then uses $100 \%$ of the tweets in the quantitative analysis, rather than a random sample (except for any possible errors in the API, in which case the sampling is at least $>95 \%$ of all relevant tweets).

${ }^{9}$ Given the 20 top hubs in each network, we qualitatively detected their tweets' sentiment towards the issues raised by \#RefugeesWelcome. In the monitored time spans, each hub authored either all pro- or all against-refugees tweets, this making the coding process straightforward. Then, we assumed that those Twitter users retweeting the hubs' tweets tended to share a similar perspective on the topic.

${ }^{10}$ Citizen: A Twitter user with less than 1,000 followers, whose Twitter profile does not highlight any specific professional qualifications.

${ }^{11}$ Social media entrepreneur: a Twitter user with over 1,000 followers, whose Twitter profile highlights their expertise in social media communications. They may also have a blog, website, Facebook page and/or Instagram profile. A social media entrepreneur need not be a professional expert in a field. Their main qualification is their large number of followers due to them being recognized as influential actors in the public sphere. 
12 News source: this category includes the Twitter profiles of news organizations/platforms, such as the official Twitter account of the BBC or Reuters, as well as the Twitter profiles of individual journalists.

${ }^{13}$ Expert: A Twitter user with a professional profile, which identifies him/her as an expert in a particular field (e.g. economist, lawyer, political analyst).

14 This category was created after an initial exploratory coding of the dataset, whereby it transpired that Pope Francis's Twitter presence was among the most influential and retweeted within the \#RefugeesWelcome Twittersphere. No other religious leader featured prominently in the sample dataset that we processed qualitatively

${ }^{15}$ Community detection consists in a network analysis technique aiming to identify subgroups of nodes, known as "communities" or "clusters" (see Blondel et al., 2008).

16 The fact that Obama is blue too is a consequence of a number of critical tweets sent by right-wing activists and mentioning Obama's profile.

${ }^{17}$ Figs. 3 and 4 were made using Yifan Hu layout in Gephi. 